\title{
FutureJournal
}

\section{A Influência do Nível de Competências e de Maturidade em Gestão de Projetos no Resultado Corporativo de uma Empresa do Setor de Transformação}

\author{
Gislaine Cristina dos Santos Teixeira \\ Mestre em Gestão de Projetos pela Universidade Nove de Julho (Uninove), Brasil \\ gislainesteixeira@gmail.com \\ Emerson Antônio Maccari \\ Doutor em Administração pela Universidade de São Paulo (USP), Brasil \\ emersonmaccari@gmail.com \\ Daniel Simonsen \\ Especialista pela Fundação Instituto de Administração, Brasil \\ daniel.simonsen@gmail.com
}

\section{RESUMO}

Os conhecimentos e as práticas em gestão de projetos contribuem com a execução estratégica e a maturidade na aplicação desta metodologia aumenta significativamente a probabilidade do sucesso de um projeto. Ainda assim, empresas que incutiram a gestão de projetos em sua estratégia têm apresentado uma série de projetos com resultados abaixo do nível satisfatório, em razão de um conjunto de fatores vinculados tanto à gestão quanto à estratégia corporativa. Este artigo tem por objetivo analisar a influência das competências e da maturidade em gestão de projetos das equipes matriciais e dos gerentes no desempenho dos projetos $\mathrm{e}$ consequentemente no resultado corporativo. A pesquisa é qualitativa, baseada no método de estudo de caso único realizado em empresa do setor de indústrias de transformação. Os principais resultados apontam para a existência de uma forte influência das competências e maturidade em gestão de projetos no desempenho operacional e nos resultados da organização.

PALAVRAS-CHAVE: Gestão de Projetos; Equipes Matriciais; Competências em Gestão de Projetos; Maturidade em Gestão de Projetos; Indústria de Transformação. 


\section{FutureJournal}

FUTURE STUDIES RESEARCH JOURNAL: TRENDS AND STRATEGIES

\section{The Influence of Competency Level and Maturity in Project Management}

in the Corporate Income of an Company of the Transformation Sector

\section{ABSTRACT}

The knowledge and project management practices contribute to the strategic execution and the maturity of these methodologies increases significantly the probability of success project. Even though, corporations, which instilled this methodology on their strategies, have tabled a number of projects showing less than satisfactory outcomes, due to set of factors linked to management and to corporate strategy implanted. This article aims to analyze the influence of competence and maturity in project management of matrix teams and managers in the results of projects and therefore on the corporate results. The research is qualitative, based on the method of single case study. The main results indicate the existence of a strong influence between skills and maturity in project management in operating performance and results of the organization.

KEY-WORDS: Project Management; Matrix Team; Project Management Competencies; Project Maturity Models; Manufacturing Industry. 


\section{INTRODUÇÃO}

O dinâmico e competitivo ambiente empresarial obriga as organizações a reverem sua forma de gestão, sendo preciso melhor definir seus objetivos e prioridades de forma a se tornarem mais eficientes e eficazes, seguindo tendência anunciada por Porter (1996, p.62): "As empresas precisam ser flexíveis para reagirem rapidamente à concorrência e às mudanças no mercado. Elas têm de adotar medições e se compararem continuamente aos concorrentes para alcançar as melhores práticas". Além disso, precisam ser habilidosas na utilização de suas competências, a fim de responderem imediatamente às novas demandas.

Considerados os setores econômicos, um importante papel é desempenhado pela indústria de transformação, também denominada indústria de processo, cujo principal propósito é adicionar valor aos materiais por meio de mistura, separação, conformação ou reações químicas (American Production and Inventory Control Society (APICS), 2010). Este tipo de indústria possui grande representatividade no desenvolvimento econômico brasileiro, tendo em vista o elevado desempenho do setor manufatureiro, comum em países não desenvolvidos ou em desenvolvimento. Porém, seus processos produtivos são complexos e requerem um grande número de mecanismos de regulação a fim de manter os elevados níveis de produção (Borges \& Dalcol, 2002). Segundo dados do Instituto de Pesquisa Econômica (IPEA) (2008), desde a década de 1980, verifica-se que a indústria de transformação brasileira diminuiu sua participação no Produto Interno Bruto (PIB) e na ocupação total do país. Entre 1985 e 2007, teve sua participação relativa reduzida para 17,6\% e em 2011 estava em 14,6\%. Esta queda desperta preocupação em termos de competitividade das empresas e também dos países. Ainda segundo IPEA, há um baixo dispêndio relativo à pesquisa e desenvolvimento e o que prevalece, no Brasil, são estratégias de inovação imitativa, nas quais parte considerável dos recursos é investida na compra de máquinas, equipamentos e serviços de terceiros.

Dentro desse contexto, este artigo busca analisar o comportamento estratégico e operacional de uma empresa que atua no ramo de serviços, oferecendo soluções integradas de engenharia, construção e montagem 
eletromecânica para atividades como implantação, modernização e manutenção de indústrias de processos. A empresa Montcalm Montagens Industriais S.A, fundada em 1971, evoluiu significativamente ao longo destes anos no uso de técnicas e ferramentas de gestão de projetos. Atualmente, lida com desafios externos como o decréscimo da participação da indústria de transformação no PIB (Confederação Nacional da Indústria (CNI), 2011) e internos, inerentes à sua própria gestão. A empresa atua com base em uma estrutura matricial e suas competências internas, processos e sistemas de gestão e monitoramento focam o cumprimento de prazos, manutenção dos padrões de qualidade e o desempenho dos projetos.

Em um ambiente global e hiper-competitivo, a gestão de projetos é um recurso para executar as operações de negócios multidisciplinares de uma maneira melhor, mais barata e mais rápida. Quando integrado a uma equipe de pessoas com ligações certas, este recurso pode transformar informações e outros insumos em resultados tangíveis, além de auxiliar a organização a lidar eficazmente com os desafios contemporâneos, tais como grupos de trabalho geograficamente dispersos, integração de trabalhos complexos, riscos e não linearidade. No entanto, o sucesso não é automático ou aleatório, pois ele depende de esforços multidisciplinares que envolvem pessoas, ambiente complexo e apoio da organização (Thamhain, 2012).

Apesar da clara importância da gestão de projetos no cerne estratégico da organização estudada, identificou-se, no decorrer do último biênio, uma série de projetos com resultados abaixo do nível satisfatório em razão de um conjunto de fatores vinculados tanto à gestão dos projetos como à estratégia corporativa implantada. Segundo Sauser, Reilly e Shenhar (2009), quando projetos importantes falham, a investigação geralmente recai no vetor técnico e de engenharia. Porém, em muitos casos, a causa da falha não é técnica e sim gerencial pois, o problema emerge de falhas na administração e na seleção da melhor abordagem para o projeto específico. Ainda sobre o resultado dos projetos, Rabechini e Pessôa (2005) ponderam que para obter sucesso é preciso esforço, pois o amadurecimento em gestão de projetos implica em decidir por uma série de ações consistentes, envolvendo o desenvolvimento de competências em várias instâncias, e isto leva tempo e tem reflexos em toda a organização. 
Tal contexto sugere avaliar se o modelo de gestão de projetos e maximização de competências adotado amplamente pela empresa analisada é adequado à gestão do negócio. A principal questão que orientou o estudo foi: Como o nível de competências e de maturidade em gestão de projetos das equipes matriciais e do gerente influencia no desempenho dos projetos e consequentemente no resultado corporativo?

Como contribuição, esta pesquisa se propõe a auxiliar os tomadores de decisão no esclarecimento de uma prática que impacta diretamente na sustentabilidade do negócio, entendendo que as lacunas de competência não preenchidas ao longo do projeto, incrementam o grau de risco de entrega dentro do custo, prazo e características previamente definidas, podendo resultar em perdas não esperadas e comprometer o resultado corporativo como um todo.

Em adição a esta seção, este artigo compreende outras cinco, a saber: (a) Revisão Bibliográfica sobre Estratégia Empresarial e Gestão de Projetos; (b) Método, que descreve a organização investigada e o delineamento da pesquisa; (c) Apresentação e Análise dos Resultados; (d) Considerações Finais e (e) Referências.

\section{REVISÃO BIBLIOGRÁFICA}

$\mathrm{Na}$ literatura científica, encontram-se diversas pesquisas e teorias relacionadas à administração dos negócios que serviriam de base para a análise da organização estudada, porém para contribuição efetiva, o referencial teórico deste trabalho está focado em dois pilares que dão suporte à análise dos dados: Estratégia Empresarial, abrangendo posicionamento e vantagem competitiva e Gestão de Projetos envolvendo a descrição dos conceitos, competências, maturidade e estrutura organizacional.

\subsection{ESTRETÉGIA EMPRESARIAL}

A chave para o sucesso competitivo está na capacidade da organização em criar valor único. Ter vantagem competitiva significa que em comparação com a concorrência, um competidor opera com um custo menor, cobra mais por seu produto, ou ainda ambos, superando o concorrente em 
termos de desempenho financeiro. A vantagem competitiva pode resultar da combinação de alguns fatores, tais como: a escolha de um conjunto de atividades internas que produzem um mix único de valor, ativos concretos ou habilidades intangíveis de tal forma que o todo tenha mais importância do que partes individuais, dificultando assim, a imitação por parte das concorrentes (Porter, 1996).

A competição atual envolve melhor satisfazer os clientes, uma tarefa muito difícil se considerarmos o aumento do nível de exigência por maior qualidade, e menor custo. As empresas precisam adotar estratégias que conquistem e mantenham a vantagem competitiva, as estratégias de custo e diferenciação (estratégias genéricas) não são mais suficientes (João \& Piscopo, 2006). Nesse sentido, o Modelo Delta de Hax e Wilde II (2002) propõe uma estratégia alternativa que permite posicionamentos que viabilizem o desempenho superior à média do setor, considerando a dinâmica do ambiente competitivo e relacionamento com o cliente. Tais autores destacam que este tipo de solução total ao cliente se baseia em um forte relacionamento que gera aprendizado mútuo (cliente e empresa), e dificulta a substituição ou imitação.

\subsection{GESTÃO DE PROJETOS}

Projeto é um empreendimento com objetivo bem definido, que consome recursos e opera sob pressões de prazos, custos e qualidade. Além disso, projetos são, em geral, considerados atividades exclusivas de uma empresa [...] A gestão de projetos pode ser definida como o planejamento, a programação e o controle de uma série de tarefas integradas de forma a atingir seus objetivos com êxito, para benefício dos participantes do projeto (Kerzner, 2007, pp.15-16).

Para o Project Management Institute (PMI) (2013), um projeto é um esforço temporário empreendido para criar um produto, serviço ou resultado exclusivo. Todos os projetos são temporários e possuem o início e o fim definidos. Tal temporalidade não significa curta duração, pois projetos podem durar de semanas a anos. Embora o projeto acabe, seu produto e resultados podem perdurar por um longo período de tempo (Carvalho \& Rabechini, 2011).

Segundo o Guia PMBOK ${ }^{\circledR}$ - Guia do Conhecimento em Gestão de Projetos (PMI, 2013), o gerenciamento de projetos possui cinco grupos de 
processos que são claramente dependentes entre si e são executados na mesma sequência em qualquer projeto, independente da área de aplicação ou setor: iniciação, planejamento, execução, controle e finalização. No decorrer do projeto, também é preciso gerenciar dez áreas de conhecimento: integração, escopo, tempo, custos, qualidade, recursos humanos, comunicações, stakeholders, riscos e aquisições. O sucesso do projeto está fortemente relacionado à gestão eficiente e eficaz destas dez áreas. Quando os projetos estão inseridos em atividades de construções ou montagens industriais, atividade central da empresa estudada, agregam-se ainda quatro outras áreas de conhecimento: segurança - que determina políticas e responsabilidades para que o projeto seja planejado e executado de maneira a prevenir acidentes e potenciais danos pessoais ou ao patrimônio; meio ambiente - responsável pelas políticas que visam minimizar o impacto do projeto no ambiente externo e nos recursos naturais, operando dentro dos limites permitidos em legislações e normas; financeira - que inclui os processos de aquisição e gerenciamento de recursos financeiros aplicáveis ao projeto; reivindicações - que descreve os processos necessários à prevenção de reivindicações construtivas, mitigação do efeito daqueles que ocorrerem e manusear reivindicações de forma ágil e efetiva.

Em seu relatório anual de 2011, que conta com a participação de dados de 754 empresas, incluindo nesta lista a própria Montcalm Montagens Industriais S.,A a PMSURVEY (2012) descreve os principais benefícios decorrentes das práticas de gerenciamento de projetos. Os três mais mencionados foram: aumento do comprometimento com objetivos $\mathrm{e}$ resultados $(67 \%)$, disponibilidade de informação para a tomada de decisão (57\%) e melhoria de qualidade nos resultados dos projetos (56\%).

Identifica-se neste meio o profissional a figura do "Gerente de Projeto", que é designado pela organização e faz uso de competências em gestão de projetos aplicando técnicas, ferramentas e conhecimentos que possibilitem estabelecer metas, balancear demandas conflitantes entre qualidade, custos, prazo e escopo e adaptar especificações, a fim de atender às expectativas e preocupações das diversas partes interessadas (PMI, 2013).

Os projetos são frequentemente utilizados como meio para que a organização conclua seu planejamento estratégico (PMI, 2013). Para a 
empresa obter vantagem competitiva, é preciso implementar uma estratégia inovadora, cuja execução pode ser viabilizada por meio dos projetos. Segundo Kerzner (2007), ainda que uma empresa possua metodologia de nível mundial em gestão de projetos, não terá condições de preencher lacunas de desempenho projetadas enquanto não possuir recursos adequados para este fim. Isso define uma forte relação entre metodologia e recursos alocados. A autora afirma ainda que, na prática, o fato de existirem metodologias estruturadas para a gestão de projetos não garantem o sucesso em si.

Neste sentido, Crawford (2010) faz uma ressalva, apesar dos benefícios do gerenciamento, os projetos podem falhar algumas vezes e duas das principais razões são: promover o melhor técnico para gerente ou não possuir processos estruturados que garantam que os gerentes sejam devidamente treinados e avaliados.

\subsubsection{Competências}

Para evoluir no uso do gestão de projetos, a organização deve considerar as camadas (indivíduos, equipes e organização). Deste modo, empresas que desejam ser mais competitivas devem gerenciar bem os projetos, administrando a competências de seus recursos, muito mais do que adotando um software de apoio (Rabechini \& Pessôa, 2005).

Em um panorama mais amplo, Brandão e Borges-Andrade (2001) afirmam que há uma rica discussão téorica sobre o conceito de competências, de tal forma que ela pode ser interpretada de múltiplas maneiras. Alguma das caracterizações constam do Quadro 1. 


\begin{tabular}{|c|c|}
\hline Autor(es) & Caracterização do "competências" \\
\hline $\begin{array}{l}\text { Boyatzis (1982, como } \\
\text { citado em Brandão \& Borges- } \\
\text { Andrade, 2001) } \\
\text { Mcclelland (1973, como } \\
\text { citado em Brandão \& Borges- } \\
\text { Andrade, 2001) }\end{array}$ & $\begin{array}{l}\text { Conjunto de qualificações ou características } \\
\text { subjacentes à pessoa, que permite que ela } \\
\text { realize determinado trabalho e gerencie uma } \\
\text { situação. }\end{array}$ \\
\hline $\begin{array}{l}\text { - Le Boterf (1999, como } \\
\text { citado em Brandão \& Borges- } \\
\text { Andrade, 2001) } \\
\text { C Zarifian (1999, como } \\
\text { citado em Brandão \& Borges- } \\
\text { Andrade, 2001) }\end{array}$ & $\begin{array}{l}\text { Não é um conjunto de atributos da pessoa, mas } \\
\text { sim suas realizações em determinado contexto, } \\
\text { ou seja, aquilo que o indivíduo realiza no } \\
\text { trabalho. }\end{array}$ \\
\hline $\begin{array}{l}\text { - Gonczi (1999, como } \\
\text { citado em Brandão \& Borges- } \\
\text { Andrade, 2001) }\end{array}$ & $\begin{array}{l}\text { Não é só um conjunto de habilidades e atitudes } \\
\text { necessários para exercer a atividade, mas } \\
\text { também o desempenho da pessoa em } \\
\text { determinado contexto. }\end{array}$ \\
\hline $\begin{array}{l}\text { Prahalad e Hamel (1990, } \\
\text { como citado em Brandão \& } \\
\text { Borges-Andrade, 2001) }\end{array}$ & $\begin{array}{l}\text { Agregam valor econômico ou social, posto que } \\
\text { contribuem com o cumprimento dos objetivos } \\
\text { organizacionais. O core competence da } \\
\text { empresa é a combinação de várias } \\
\text { competências que oferecem benefício ao } \\
\text { comsumidor, sendo difícil de imitar. }\end{array}$ \\
\hline (2000) Dutra, Hipólito e Silva, & $\begin{array}{l}\text { Capacidade de a pessoa gerar resultados } \\
\text { dentro dos objetivos estratégicos e } \\
\text { organizacionais da empresa, traduzindo-se pelo } \\
\text { mapeamento do resultado esperado e do } \\
\text { conjunto de conhecimentos, habilidades e } \\
\text { atitudes necessários para o seu atingimento. }\end{array}$ \\
\hline Ruas (2005) & $\begin{array}{l}\text { Envolve três dimensões principais: } \\
\text { organizacional, funcional e individual/gerência. } \\
\text { A noção principal de competência aproxima-se } \\
\text { da capacidade de combinar e mobilizar } \\
\text { adequadamente habilidades conhecimentos e } \\
\text { colocá-los em ação numa determinada situação } \\
\text { real, preferencialmente na própria atividade } \\
\text { profissional. }\end{array}$ \\
\hline Fleury e Fleury (2001) & $\begin{array}{l}\text { Se por um lado a noção de competência agrega } \\
\text { valor à organização, por outro, ela deve } \\
\text { agregar valor social ao indivíduo, ou seja, as } \\
\text { pessoas, ao desenvolverem competências } \\
\text { essenciais para o sucesso da organização, } \\
\text { estão também investindo em si mesmas. }\end{array}$ \\
\hline
\end{tabular}

\section{Quadro 1: Caracterização do termo "competências"}

Fonte: Elaborado pelos autores

Com relação aos tipos de competências em gestão de projetos, Frame (1999, como citado em Rabechini \& Pessôa, 2005) sugere três: (a) aptidões e habilidades do indivíduo em solucionar problemas de projetos; (b) competências da equipe em resolver problemas complexos em contexto multidisciplinar e (c) competências da empresa para criar um ambiente que 
possibilite o envolvimento do indivíduo e das equipes para tocar os projetos de forma eficaz. Rabechini e Pessôa (2005) complementam esta visão afirmando que os indivíduos devem dominar as técnicas e as ferramentas com uma visão bastante abrangente das necessidades do projeto, as equipes devem ser proativas e manterem-se focadas no cumprimento dos objetivos do projeto e a organização deve institucionalizar as práticas de gestão de projetos.

\subsubsection{Maturidade}

Investir na gestão de projetos está sendo uma preocupação estratégica das organizações que passam por uma curva de aprendizagem até atingir a maturidade no uso da metodologia e neste contexto, a maturidade é o desenvolvimento de sistemas e processos repetitivos que garantem uma alta probabilidade de que cada projeto obtenha sucesso (Kerzner, 2007). O autor sugere ainda que para uma empresa alcançar a excelência em gestão de projetos, deve passar por cinco níveis: 1) linguagem comum, no qual a organização reconhece a importância do gerenciamento de projetos como metodologia útil para atingir o sucesso; 2) processos comuns que visam replicar o sucesso de um projeto nos demais; 3) metodologia singular, quando a organização reconhece a possibilidade de obter sinergia com a combinação de várias metodologias; 4) benchmarking, processo contínuo de comparação das práticas de gestão de projetos desenvolvidas por outras organizações e 5) melhoramento contínuo a partir do que foi aprendido. Estas fases também podem ser genericamente nomeadas como: embrionária, reconhecimento da alta administração, reconhecimento da média gerência, crescimento e maturidade.

O PMI (1999) propõe outro modelo de maturidade que referencia as principais capacitações inerentes à gestão de projetos - o modelo OPM3 - que descreve as seguintes fases: 1) padronização e integração de métodos e processos, visando o estabelecimento de uma linguagem comum a ser praticada por todos; 2) desenvolvimento de métricas para medir o desempenho dos projetos quanto a prazo/custo/qualidade; 3) comprometimento com procedimentos de gerenciamento de projetos; 4) priorização de projetos alinhados a estratégia organizacional; 5) 
melhoramento contínuo visando a acessibilidade às lições aprendidas; 6) estabelecer os critérios de sucesso; 7) criar mecanismos para avaliar a competência dos recursos/equipes de projetos; 8) alocação adequada de pessoal segundo as estratégias organizacionais; 9) aspectos organizacionais, estruturação das equipes de projetos considerando-se as formas organizacionais existentes; 10) equipes, formação de cultura baseada em equipes de projetos, considerando-se inovação e criatividade de trabalhos. Para Bouer e Carvalho (2005), o gerenciamento de projetos não é simplesmente uma metodologia e o seu domínio estratégico inclui sistemas que assegurem a entrega dos múltiplos projetos da organização; o modelo deve ainda adequar atividades, prioridades estratégicas e da infraestrutura; fortalecer o vínculo entre estratégia organizacional e execução, aumentando a taxa de sucesso dos projetos; incluir capacidades que diferenciem a organizações das demais e as rotinas organizacionais devem estar alinhadas ao gerenciamento de portfólio, priorizando projetos alinhados à estratégia.

\subsubsection{Estrutura Organizacional}

A estrutura de uma organização pode ser definida como o resultado de um processo através do qual a autoridade é distribuída, as atividades desde os níveis mais baixos até a alta administração são especificadas e um sistema de comunicação é delineado permitindo que as pessoas realizem atividades e exerçam a autoridade que lhes compete para o atingimento dos objetivos organizacionais (Vasconcellos \& Hemsley, 2002, p.3).

O aumento da turbulência no ambiente empresarial, tornou muitas das estruturas tradicionais inadequadas, surgiram então estruturas inovativas, que respondem de forma mais ágil às mudanças, entre elas a estrutura matricial (Vasconcellos \& Hemsley, 2002). Corroborando com este posicionamento, sob a ótica de projetos, Kerzner (2007) destaca que nos últimos anos, os executivos perceberam que as organizações devem ser mais dinâmicas, sendo capazes de se reestruturar rapidamente, o que pode demandar adoção de novos formatos hierárquicos.

Para o PMI (2013, p. 28): "A estrutura organizacional é um fator ambiental da empresa que pode afetar a disponibilidade dos recursos e influenciar a maneira como os projetos são conduzidos. As estruturas variam de funcionais a projetizadas, com diversas estruturas matriciais". As 
matriciais fracas se aproximam muito de uma estrutura funcional e o papel do gerente é parecido com o de um coordenador ou facilitador. As matriciais fortes possuem muitas características de organizações projetizadas e podem ter gerentes de projeto em tempo integral com autoridade sobre o pessoal administrativo para trabalhar em algum projeto em tempo integral. A matricial balanceada reconhece a necessidade do gerente, mas este não tem autoridade total sobre o projeto. Kerzner (2009) identificou fatores que influenciam a escolha da estrutura organizacional, entre eles: tamanho do projeto, duração do projeto, localização física do projeto, recursos disponíveis e aspectos específicos do projeto, experiência da organização na gestão de projetos, filosofia da alta gestão da empresa quanto ao gerenciamento de projetos, sendo os dois últimos relacionados à maturidade da empresa em gerenciamento de projetos.

\section{MÉTODO DE PESQUISA}

Esta é uma pesquisa aplicada, de abordagem qualitativa, natureza exploratória descritiva e o método utilizado para a sua condução foi o estudo de caso único. Visando a construção de plataforma teórica sobre o assunto e seguindo as recomendações de Martins e Theóphilo (2009), iniciou-se pela pesquisa bibliográfica, que envolveu levantar estudos já publicados sobre os temas relacionados à questão de pesquisa. Em seguida, adotou-se a abordagem denominada estudo de caso único: uma investigação empírica que analisa em profundidade um fenômeno contemporâneo em seu contexto de vida real (Yin, 2010, p.39).

O estudo empírico buscou identificar até que ponto, o modelo de gestão de projetos utilizado pela Montcalm Montagens Industriais S. A atende ao nível de maturidade e competências em gerenciamento de projetos necessários ao sucesso corporativo. A relevância do caso é pautada no histórico de atuação da empresa, cujo portfólio de projetos inclui mais de 4.000 obras realizadas para cerca de 1.300 indústrias de cimento, mineração, papel e celulose, têxteis, química e petroquímica, fertilizantes, óleo e gás, geração de energia, metalurgia. Além disso, a Montcalm consta como uma das 754 empresas mundiais que empregam metodologia de gestão de projetos em sua estratégia (PMSURVEY, 2012). O processo de escolha da 
organização foi simbiótico, por um lado existia o domínio das características e o conhecimento dos projetos da empresa, além da facilidade de acesso às informações por parte dos pesquisadores, e por outro, existia a percepção dos representates da organização que, discussões acerca da metodologia poderiam contribuir com o desempenho dos projetos.

A fim de triangular os dados, os pesquisadores procederam a uma pesquisa exploratória baseada na coleta de dados secundários, a partir da análise de documentos cedidos pela empresa (Manual do Gerente de Projetos, relatórios e web sites) e também primários, obtidos por meio da aplicação de questionário individual. Como o objetivo era confrontar a literatura da gestão de projetos com às práticas da empresa, o formulário foi direcionado exclusivamente aos gerentes de projetos atuantes na organização. 0 universo da amostra selecionada continha 22 funcionários. O formulário estruturado foi distribuído por meio eletrônico, sendo que deste universo, 19 profissionais o devolveram preenchido, correspondendo a $86,3 \%$ da amostra.

\subsection{INSTRUMENTO DE PESQUISA}

A partir da revisão bibliográfica de dos documentos fornecidos pela empresa, elaborou-se o instrumento de pesquisa descrito no Quadro 2:

\begin{tabular}{|c|c|c|c|}
\hline $\begin{array}{c}\text { Objetivo da } \\
\text { Pesquisa }\end{array}$ & Variáveis & $\begin{array}{c}\text { Formulário } \\
\text { Estruturado }\end{array}$ & $\begin{array}{c}\text { Itens do } \\
\text { Instrumento de } \\
\text { Coleta de Dados }\end{array}$ \\
\hline \multirow{3}{*}{$\begin{array}{l}\text { Identificar a } \\
\text { influência do } \\
\text { nível de } \\
\text { competências e } \\
\text { maturidade em } \\
\text { gestão de } \\
\text { projetos das } \\
\text { equipes } \\
\text { matriciais e do } \\
\text { gerente no } \\
\text { resultado do } \\
\text { projeto }\end{array}$} & $\begin{array}{l}\text { - Nível de integração entre as áreas de apoio } \\
\text { matricial e o gerente do projeto. } \\
\text { - Vinculação das competências em projetos } \\
\text { atreladas a cada área estrutural. }\end{array}$ & $\begin{array}{c}10 \text { Formulário } \\
\text { estruturado }\end{array}$ & Itens 1 a $13^{*}$ \\
\hline & $\begin{array}{l}\text { - Nível de competências e maturidade em } \\
\text { projetos da equipe matricial disponível para } \\
\text { apoio à gerência de projetos. } \\
\text { - Competências em gerenciamento de } \\
\text { projetos mais importantes para o resultado. }\end{array}$ & $\begin{array}{c}20 \text { Formulário } \\
\text { estruturado }\end{array}$ & Itens 1 a $24^{*}$ \\
\hline & $\begin{array}{l}\text { - Integração entre métodos padronizados na } \\
\text { organização e gestão de projetos. } \\
\text { - Grau de familiaridade dos gerentes com } \\
\text { estes métodos. }\end{array}$ & $\begin{array}{c}20 \text { Formulário } \\
\text { estruturado }\end{array}$ & Itens 25 a $32 *$ \\
\hline
\end{tabular}

* Itens identificados por letras

Quadro 1: Instrumento de Pesquisa

Fonte: Elaborado pelos autores

Foi efetuada uma análise qualitativa das respostas apresentadas nos questionários. Dado o fato de o questionário ter sido preenchido por cada um 
dos profissionais individualmente, sem esclarecimento prévio, era passível o preenchimento incorreto, com respostas distintas das esperadas para o tema abordado. Nestas circunstâncias, expurgou-se da amostra um total de dois questionários respondidos incorretamente, consolidando uma base de 16 dos 22 formulários enviados, correspondendo a 72,72\% de amostras válidas dentro do universo total de formulários.

\section{APRESENTAÇÃO E ANÁLISE DOS RESULTADOS}

Os resultados serão apresentados em duas subseções: (a) Caracterização da Organização e (b) Maturidade e Competência em Gestão de Projetos.

\subsection{CARACTERIZAÇÃO DA ORGANIZAÇÃO}

A Montcalm Montagens Industriais S.A. é uma empresa do grupo Intercept Participações que atua no ramo de serviços, oferecendo soluções integradas de engenharia, construção e montagem eletromecânica para implantação, modernização e manutenção de indústrias de processos. A sede da empresa está instalada em São Paulo - Capital e concentra a gestão corporativa da organização. A empresa também conta com uma central logística, responsável pelo gerenciamento dos ativos operacionais e recursos de obras da empresa. A Montcalm promoveu uma reestruturação interna, partindo de uma estrutura matricial balanceada, modelo praticado até o ano de 2007, para uma estrutura matricial forte, modelo consolidado na empresa no ano de 2008 e que vigora até o presente momento. Neste mesmo período, a empresa adotou o Guia $\mathrm{PMBOK}^{\circledR}$ como padrão de práticas de gestão de projetos e criou o seu próprio Manual do Gerente de Projetos, respeitando os preceitos do PMI.

Neste período, estruturou-se o Departamento de Operações (DOP) representado pelo Diretor de Operações, responsável por chefiar os gerentes de projeto. Promoveu então, a hierarquização dos gerentes de projetos e a definição da estrutura matricial de apoio à gestão de projetos: Planejamento, Controladoria, Recursos Humanos, Qualidade, Jurídico, Compras/Aquisições, 
Suprimentos e Logística Interna. A empresa possui um quadro de aproximadamente 4.000 funcionários envolvidos em uma média de vinte projetos com execução simultânea.

A partir da coleta e análise de dados financeiros gerenciais, no período de 2000 a 2012, foi possível verificar uma tendência de queda na quantidade de projetos ativos, de 225 em 2000, para 32 em 2012. Apesar do afunilamento do portfólio, houve uma evolução do faturamento da empresa, sinal da incorporação de projetos com valores financeiros sistematicamente superiores. Constatou-se também queda no resultado corporativo. A evolução do valor médio dos projetos da empresa caracteriza, analogamente, exigências superiores de competências gerenciais e maturidade plena em processos padronizados e estruturados na organização. Projetos maiores passaram a exigir conhecimentos em outras esferas além da técnica, demandando do gerente conhecimento relacionado à esfera política, jurídica, relações sindicais e análise mais profunda de riscos inerentes aos projetos, estruturação de KPIs, também conhecidos como Indicadores Chave de Performance.

\subsection{COMPETÊNCIA E MATURIDADE EM GESTÃO DE PROJETOS}

A coleta de dados buscou identificar a percepção dos gerentes de projetos da Montcalm quanto aos seguintes aspectos: (a) nível de integração deste com as áreas de apoio matricial, a partir da vinculação das competências atreladas a cada área estrutural e (b) influência do nível de competência e de maturidade em gestão de projetos tanto das áreas de apoio as próprias, no desempenho dos projetos da empresa. Os gráficos e quadros na sequência demonstram o resultado da coleta de dados. 


\section{Resultados obtidos - Pesquisa de Percepção de Apoio Matricial}

Apoio matricial em Competências Gerais

(A) - Avaliação da necessidade de recursos ao projeto, qualitativa e quantitativamente, em decorrência do grau de maturidade, competência e complexidade exigidos pelo projeto, para as áreas de apoio técnico como Qualidade/Planejamento/Engenharia (B) - Avaliação da necessidade de recursos ao projeto, qual itativa e quantitativamente, em decorrência do grau de maturidade, competência e complexidade exigidos pelo projeto, para atividades de RH / Financeiro / $\mathrm{Tl} /$ Controladoria

(C) - Definição de recursos dos departamentos de apoio, oriundos das avaliações acima e de uma análise crítica de riscos inerentes ao projeto

(D) - Auditorias internas para conformidade com normas e padrões definidos para o projeto (procedimentos corporativos/normas aplicáveis/planos)

\section{Apoio matricial Competências relacionadas à Gestão da Qualidade}

(E) - Análise crítica das competências dos recursos de qualidade / planejamento / compras / RH alocados no projeto

(F) - Execução de adequações de equipe para eliminar / minimizar riscos atrelados ao projeto relacionados às lacunas de competência das equipes de apoio acima mencionadas

(G) - Avaliação crítica dos critérios e especificação contratuais para elaboração da documentação de qualidade executiva do projeto (H) - Identificação e análise de risco / impacto de desvios de execução em rel ação ao previsto em especificações do projeto

(1) - Elaboração de documentação do controle da qualidade (procedimentos, consultas técnicas, fluxogramas operacionais) aplicáveis ao projeto

(J)- Auditorias internas para conformidade com normas e padrões definidos para o projeto (procedimentos corporativos / normas aplicáveis/planos)

\section{Apoio matricial Competências relacionadas à Gestão do Planejamento}

( K) - Elaboração dos cronogramas executivos e planos de trabalho aplicáveis ao projeto

( L) - Elaboração e padronização da documentação de planejamento a ser utilizada no projeto, inclu indo aprovação desta com os stakeholders diretamente envolvidos no projeto (clientes internos / externos)

(M) - Auditorias internas para averiguação da conformidade com planos executivos definidos para o projeto e elaboração de planos de ação para correção de desvios identificados

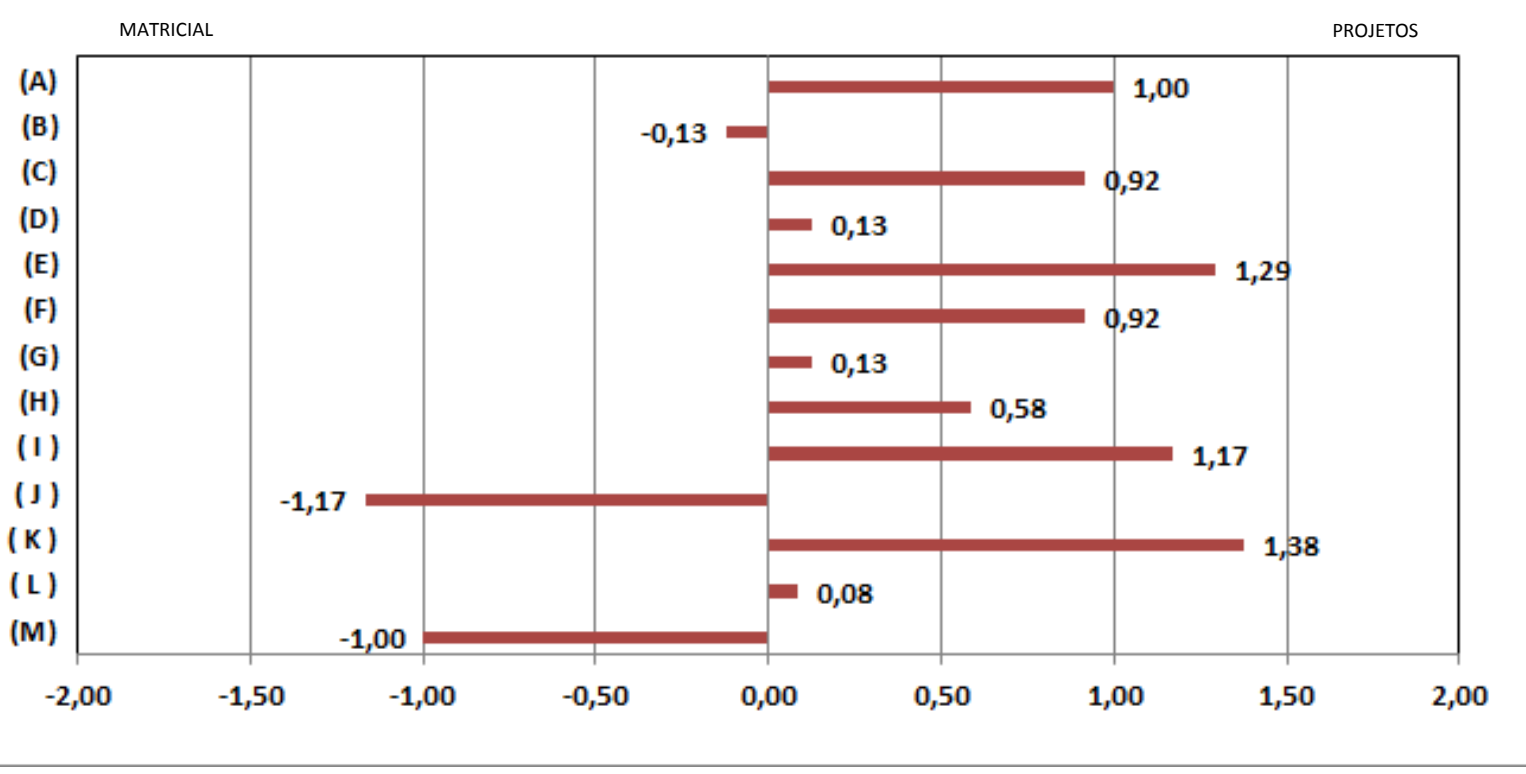

Figura 1: Avaliação de Percepção de Apoio Matricial - $1^{0}$ Formulário Fonte: Elaborada pelos autores

A Figura 1 apresenta o resultado consolidado da média das avaliações obtidas a partir das repostas dos gerentes de projeto ao primeiro formulário. O valor plotado no gráfico representa a percepção do nível de participação e integração das equipes de apoio matricial que os gerentes consideram como adequadas ou ótimas para as atividades citadas.

A escala -2 a 2 refere-se ao nível de responsabilidade e de atuação que a unidade matricial deveria assumir para funções essenciais, identificadas 
pelas letras (A) até (M). Verifica-se, a partir do gráfico, a existência de atividades que são fortemente desempenhadas ou de forte responsabilidade matricial, como por exemplo, as atividades de auditoria, identificadas pelas letras (J) e (M), bem como atividades de forte responsabilidade da área de projetos: $(A),(E),(I)$ e $(K)$. As outras atividades, identificadas entre as notas -1 e 1 suscitam uma responsabilidade mútua, sugerindo forte integração entre a equipe matricial e a equipe de projetos. Este diagnóstico é essencial para que a organização possa analisar e possivelmente melhorar seu modelo de participação e integração de competências em gestão de projetos.

Os gráficos representados pelas Figuras 2, 3, 4 e 5 demonstram a tabulação dos dados obtidos a partir do segundo formulário estruturado da pesquisa aplicado nas áreas consideradas essenciais, segundo os representantes da organização, para o desenvolvimento de qualquer tipo de projeto: Qualidade, Planejamento e Recursos Humanos. Estes gráficos ilustram o resultado consolidado da média das avaliações obtidas. A Escala Likert (1 a 5) foi utilizada para avaliar uma série de itens de desempenho relacionados à gestão de projetos, bem como seu respectivo grau de importância. 
Avaliação de Nível de Desempenho - Área Controle da Qualidade

- Nivel de Desempenho = Grau de Importância

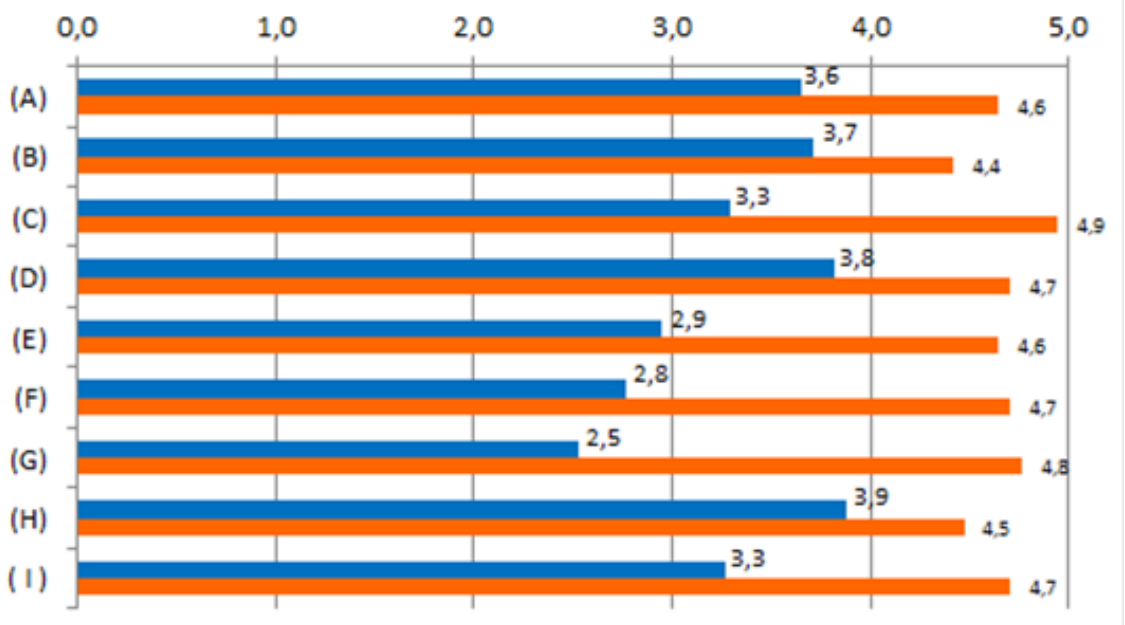

(A) Existe apoio em termos de liderança no processo de qualidade, com o fornecimento de gestão e de conhecimento estratégicos, que claramente estão alinhados com os objetivos do projeto.

(B) Existe o suporte pleno dos itens acima fornecidos pela gerência do departamento.

(C) O departamento de qualidade do projeto tem condições e competências para analisar criticamente a documentação do projeto e promover a estruturação de documentos e procedimentos para o atendimento às exigências contratuais no quesito da qualidade.

(D) A equipe de qualidade tem competência para elaboração de relatórios de monitoramento e controle, tais como: índice de desempenho de soldagem, índice de fechamento de RNC, entre outros, de maneira assertiva e adequados às particularidades do projeto.

(E) A equipe de qualidade utiliza os dados estratificados nestes relatórios, propondo desdobramentos e planos de ação em circunstâncias nas quais a meta estabelecida não é cumprida, por meio de análise crítica fundamentada.

(F) O departamento de controle da qualidade analisa criticamente o escopo e tem competência para identificar previamente pontos críticos dentro das obrigações de execução, merecedores de desenvolvimento de processos, procedimentos, assessorias e outros.

(G) Após identificação destes pontos, o controle da qualidade efetua de maneira assertiva o desdobramento de ações para estruturação dos procedimentos, convocações de assessoria e desenvolvimento de processos para garantir que estes estejam implantados antes da execução da atividade propriamente dita.

(H) O controle de RQS do projeto realizado pelo departamento de qualidade atende plenamente as demandas e necessidades do projeto.

(I) De uma maneira ampla, avalie o nível de competência e maturidade da disciplina de Controle da Qualidade dentro do seu projeto.

Figura 2: Avaliação de Itens de Desempenho da Área Controle da Qualidade Fonte: Elaborada pelos autores 


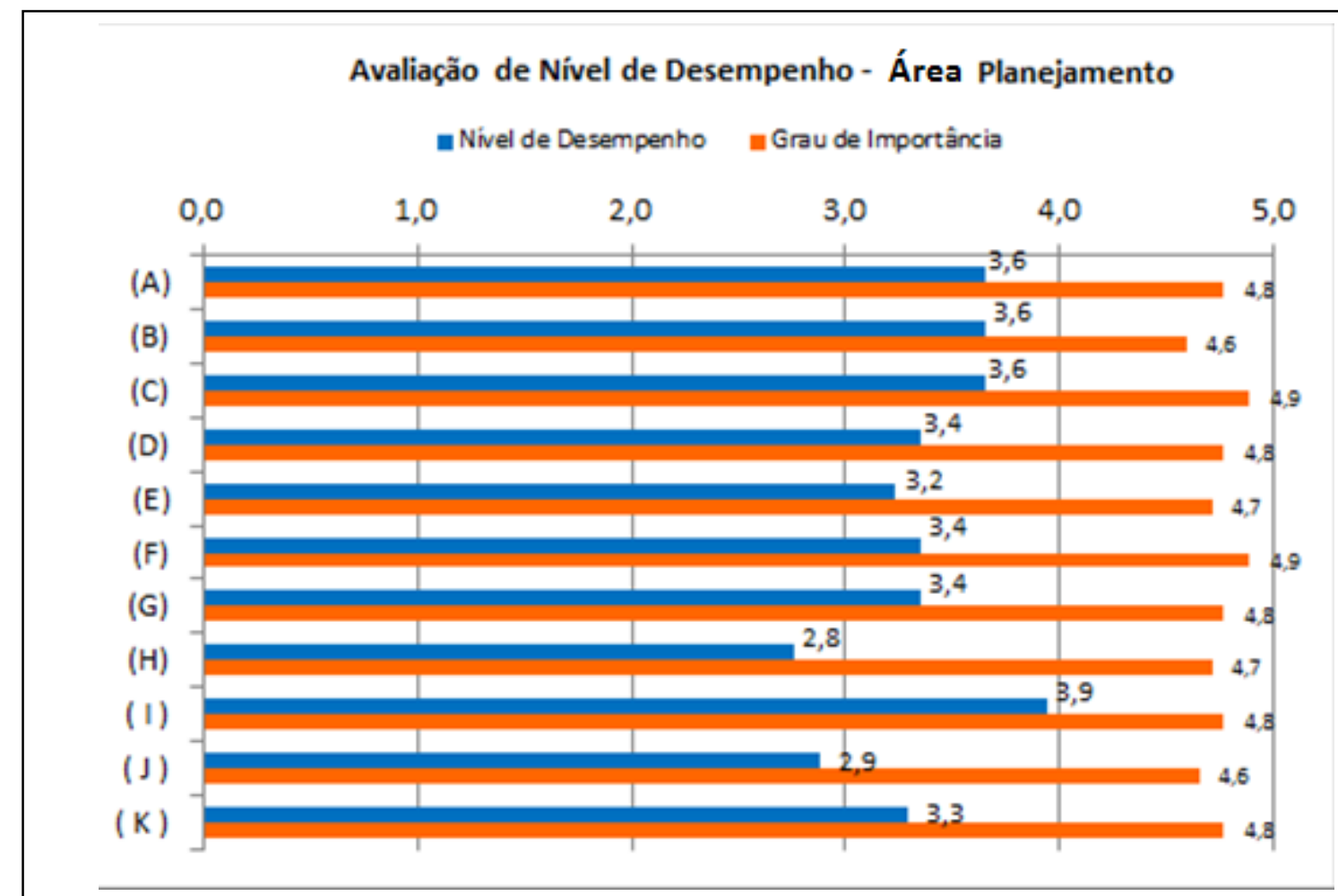

(A) Existe apoio em termos de liderança no processo de planejamento, com fornecimento de gestão e de conhecimento estratégicos, que claramente estão alinhados com os objetivos do projeto.

(B) Existe o suporte pleno dos itens acima fornecidos pela gerência do departamento.

(C) O projeto dispõe de setor de planejamento com competência e habilidade para estruturação e elaboração de Cronogramas e Histogramas assertivos.

(D) O projeto dispõe de setor de planejamento com competência para estruturação e elaboração de programações periódicas assertivas.

(E) O arquivo técnico possui competência para atuação produtiva e eficiente quanto à distribuição de documentação do projeto às partes interessadas e promove a substituição das cópias controladas à medida que novas revisões são emitidas.

(F) As medições emitidas pelo departamento estão coincidentes com os prazos estabelecidos e representando fielmente o escopo de medição aplicável ao período.

(G) O departamento de planejamento do projeto tem condições e competências para analisar criticamente a documentação do projeto e promover a estruturação de documentos e procedimentos para o atendimento às exigências contratuais dentro deste quesito.

(H) As atividades relacionadas à gestão e controle de materiais (quantidades em estoque, inventários, agilidade na localização, agilidade no atendimento a solicitações) satisfazem plenamente as necessidades do projeto.

(I) A equipe de planejamento tem competência para elaboração de relatórios de gestão, como Curva S e Relatórios de Eficiência, de maneira assertiva com projeções realistas ajustadas à realidade do projeto.

(J) A equipe de planejamento utiliza os dados estratificados destes relatórios de gestão, propondo desdobramentos e planos de ação em circunstâncias nas quais a meta estabelecida não é cumprida, por meio de análise crítica fundamentada.

(K) De uma maneira ampla, avalie o nível de competência e maturidade da disciplina de Planejamento dentro do seu projeto.

Figura 3: Avaliação de Itens de Desempenho da Área Planejamento Fonte: Elaborada pelos autores 


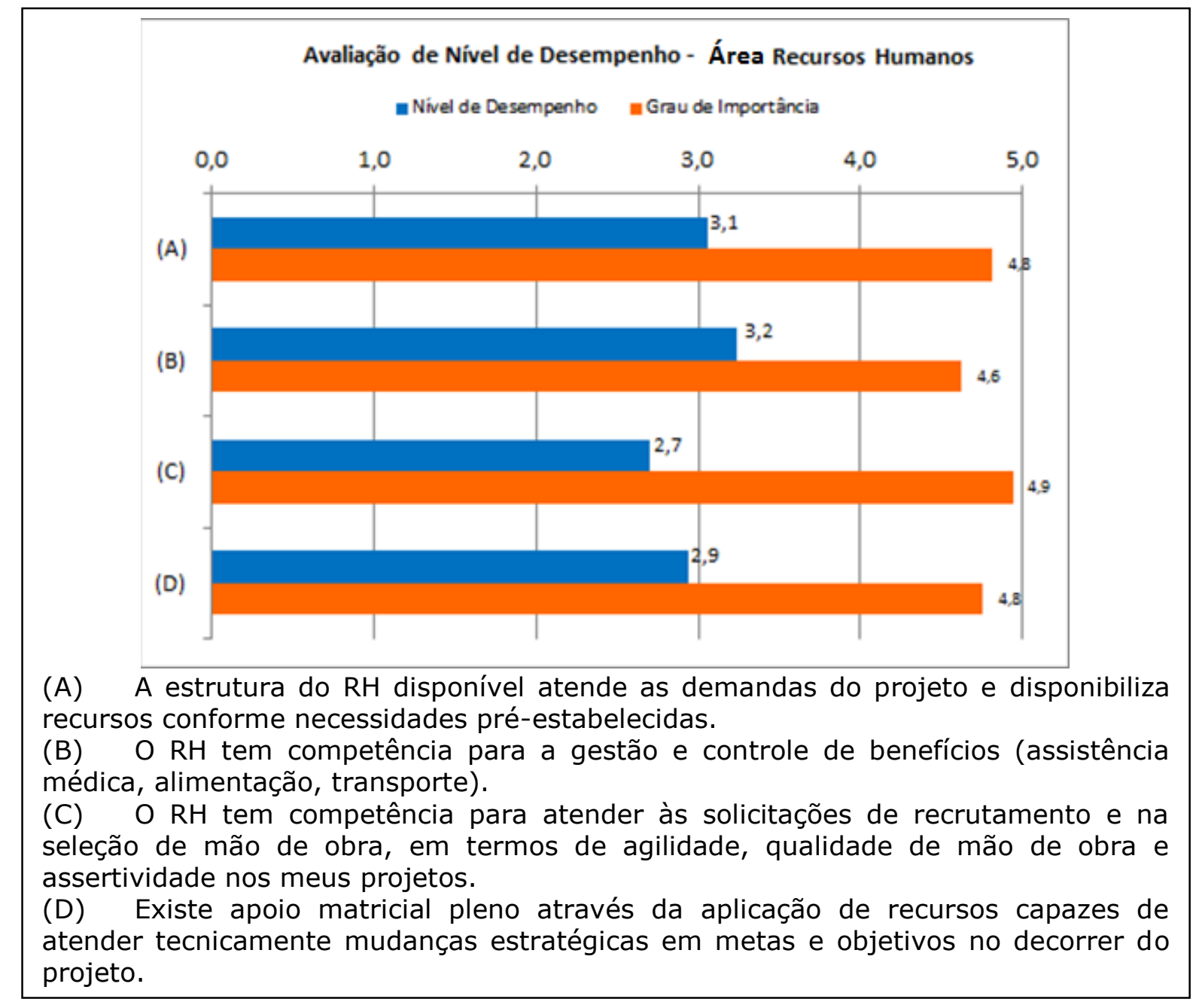

Figura 4: Avaliação de Itens de Desempenho da Área Recursos Humanos Fonte: Elaborada pelos autores 


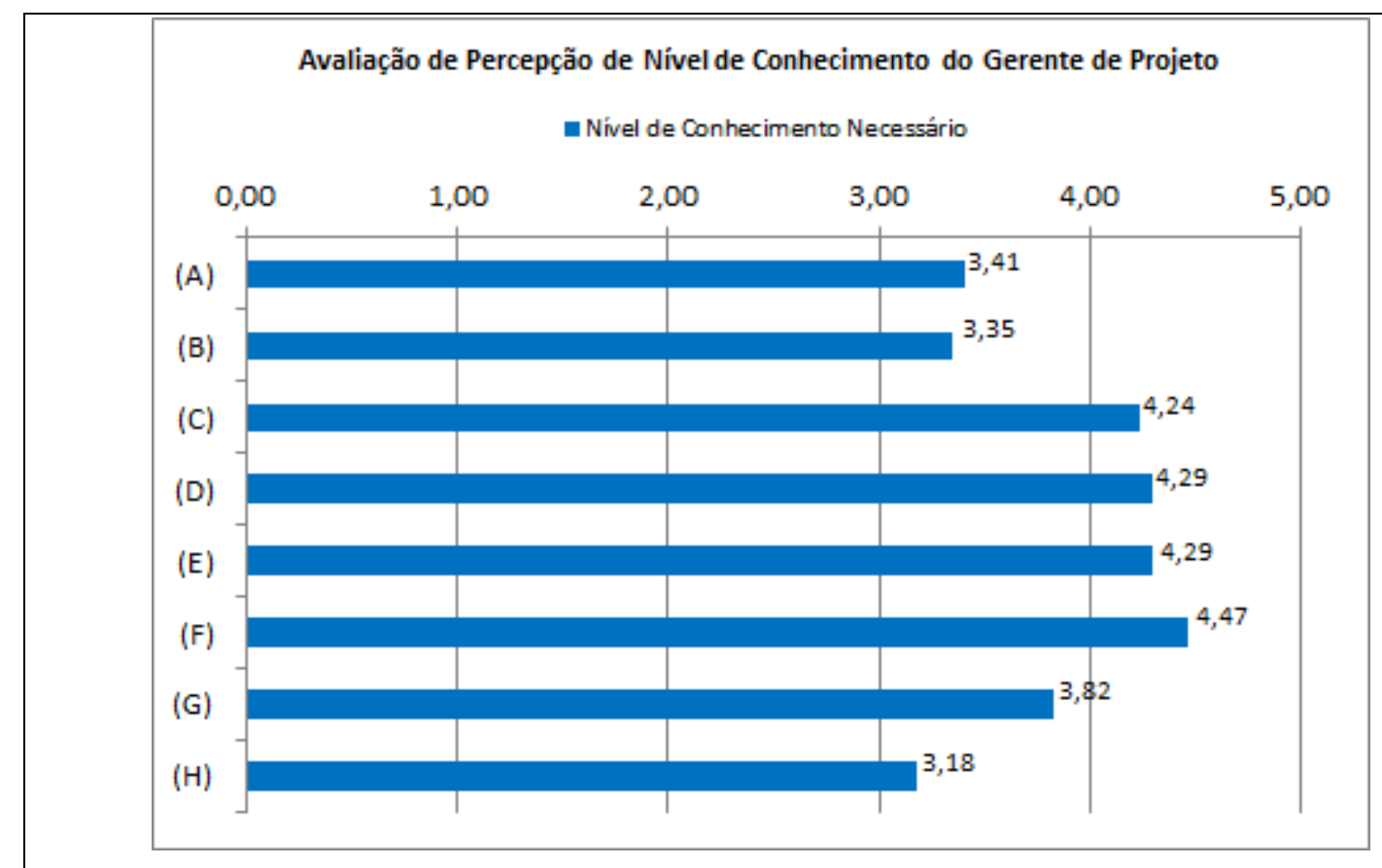

(A) Grau de entendimento que o Gerente de Projetos deve ter nos sistemas de Controle de Qualidade do projeto (SisRNC; SisSolda; SGP).

(B) Grau de entendimento que o Gerente de Projetos deve ter nos sistemas de Planejamento aplicados no projeto (Primavera; Contract Manager; SGP; SisMat; SisCon).

(C) Nível de competência técnica necessária a um Gerente de Projetos em relação à interpretação de documentos e entendimento das exigências técnicas de Controle da Qualidade.

(D) Nível de competência técnica necessária a um Gerente de Projetos em relação ao entendimento das exigências contratuais do Controle da Qualidade.

(E) Competência técnica necessária a um Gerente de Projetos em relação à interpretação de documentos e entendimento das exigências técnicas de Planejamento.

(F) Nível de competência técnica necessária a um Gerente de Projetos em relação ao entendimento das exigências contratuais do Planejamento.

(G) De uma maneira ampla, avalie o nível de habilidades técnicas dos Gerentes de Projetos da Montcalm (dentro das áreas de conhecimento do $\mathrm{PMBOK}^{\circledR}$ ).

(H) Nível de utilização do repositório existente (base de obras executadas, base de documentos) pelos Gerentes de Projetos.

Figura 5: Avaliação do Nível de Conhecimento do Gerente de Projetos

Fonte: Elaborada pelos autores

A partir da análise dos gráficos apresentados anteriormente, foi possível identificar os itens que apresentaram maior índice relativo de risco à organização: 


\begin{tabular}{|c|c|c|c|}
\hline Área de Apoio & Item de Apoio & \begin{tabular}{|c|} 
Nível \\
Relativo \\
de Risco \\
Potencial*
\end{tabular} & $\begin{array}{c}\text { Classificação } \\
\text { por nível de } \\
\text { risco } \\
\text { potencial }\end{array}$ \\
\hline Qualidade & $\begin{array}{l}\text { Após identificação destes pontos, o } \\
\text { controle da qualidade efetua de maneira } \\
\text { assertiva o desdobramento de ações para } \\
\text { estruturação dos procedimentos, } \\
\text { convocações de assessoria e } \\
\text { desenvolvimento de processos para } \\
\text { garantir que estes estejam implantados } \\
\text { antes da execução da atividade } \\
\text { propriamente dita. (G) }\end{array}$ & 12,00 & 10 \\
\hline Qualidade & $\begin{array}{l}\text { O departamento de controle da qualidade } \\
\text { analisa criticamente o escopo e tem } \\
\text { competência para identificar previamente } \\
\text { pontos críticos dentro das obrigações de } \\
\text { execução, merecedores de } \\
\text { desenvolvimento de processos, } \\
\text { procedimentos, assessorias e outros. (F) }\end{array}$ & 13,16 & 20 \\
\hline Qualidade & $\begin{array}{l}\text { A equipe de qualidade utiliza os dados } \\
\text { estratificados nestes relatórios, propondo } \\
\text { desdobramentos e planos de ação em } \\
\text { circunstâncias nas quais a meta } \\
\text { estabelecida não é cumprida, por meio de } \\
\text { análise crítica fundamentada. (E) }\end{array}$ & 13,34 & 30 \\
\hline Planejamento & $\begin{array}{l}\text { As atividades relacionadas à gestão e } \\
\text { controle de materiais (quantidades em } \\
\text { estoque, inventários, agilidade na } \\
\text { localização, agilidade no atendimento a } \\
\text { solicitações) satisfazem plenamente as } \\
\text { necessidades do projeto. (H) }\end{array}$ & 13,16 & 10 \\
\hline Planejamento & $\begin{array}{l}\text { A equipe de planejamento utiliza os dados } \\
\text { estratificados destes relatórios de gestão, } \\
\text { propondo desdobramentos e planos de } \\
\text { ação em circunstâncias nas quais a meta } \\
\text { estabelecida não é cumprida, por meio de } \\
\text { análise crítica fundamentada. (J) }\end{array}$ & 13,34 & 20 \\
\hline $\begin{array}{l}\text { Recursos } \\
\text { Humanos }\end{array}$ & $\begin{array}{l}\text { O RH tem competência para atender às } \\
\text { solicitações de recrutamento e na seleção } \\
\text { de mão-de-obra, em termos de agilidade, } \\
\text { qualidade de mão de obra e assertividade } \\
\text { nos meus projetos. (C) }\end{array}$ & 13,23 & 10 \\
\hline $\begin{array}{l}\text { Recursos } \\
\text { Humanos }\end{array}$ & $\begin{array}{l}\text { Existe apoio matricial pleno através da } \\
\text { aplicação de recursos capazes de atender } \\
\text { tecnicamente mudanças estratégicas em } \\
\text { metas e objetivos no decorrer do projeto. } \\
\text { (D) }\end{array}$ & 13,92 & 20 \\
\hline
\end{tabular}

Quadro 2: Itens com alto nível relativo de risco potencial para a organização Fonte: Elaborado pelos autores

Também foi possível identificar os itens que apresentam maior potencial relativo à eficiência e vantagem operacional da organização: 


\begin{tabular}{|c|c|c|c|}
\hline Área de Apoio & Item de Apoio & \begin{tabular}{c|} 
Nível relativo de \\
Eficiência e \\
Vantagem \\
Operacional* \\
\end{tabular} & $\begin{array}{c}\text { Classificação } \\
\text { por nível de } \\
\text { vantagem } \\
\text { potencial } \\
\end{array}$ \\
\hline Qualidade & $\begin{array}{l}\text { A equipe de qualidade tem competência } \\
\text { para elaboração de relatórios de } \\
\text { monitoramento e controle, tais como: } \\
\text { índice de desempenho de soldagem, } \\
\text { índice de fechamento de RNC, entre } \\
\text { outros, de maneira assertiva e } \\
\text { adequados às particularidades do } \\
\text { projeto. (D) }\end{array}$ & 17,86 & 10 \\
\hline Qualidade & $\begin{array}{l}\text { O controle de RQS do projeto realizado } \\
\text { pelo departamento de qualidade atende } \\
\text { plenamente as demandas e } \\
\text { necessidades do projeto. }(\mathrm{H})\end{array}$ & 17,55 & 20 \\
\hline Qualidade & $\begin{array}{l}\text { Existe apoio em termos de liderança no } \\
\text { processo de qualidade, com o } \\
\text { fornecimento de gestão e de } \\
\text { conhecimento estratégicos, que } \\
\text { claramente estão alinhados com os } \\
\text { objetivos do projeto. (A) }\end{array}$ & 16,56 & 30 \\
\hline Qualidade & $\begin{array}{l}\text { Existe o suporte pleno dos itens acima } \\
\text { fornecidos pela gerência do } \\
\text { departamento. (B) }\end{array}$ & 16,28 & 40 \\
\hline Planejamento & $\begin{array}{l}\text { A equipe de planejamento tem } \\
\text { competência para elaboração de } \\
\text { relatórios de gestão, como Curva S e } \\
\text { Relatórios de Eficiência, de maneira } \\
\text { assertiva com projeções realistas } \\
\text { ajustadas à realidade do projeto. (I) }\end{array}$ & 18,72 & 10 \\
\hline Planejamento & $\begin{array}{l}\text { O projeto dispõe de setor de } \\
\text { planejamento com competência e } \\
\text { habilidade para estruturação e } \\
\text { elaboração de Cronogramas e } \\
\text { Histogramas assertivos. (C) }\end{array}$ & 17,64 & 20 \\
\hline Planejamento & $\begin{array}{l}\text { Existe apoio em termos de liderança no } \\
\text { processo de planejamento, com } \\
\text { fornecimento de gestão e de } \\
\text { conhecimento estratégicos, que } \\
\text { claramente estão alinhados com os } \\
\text { objetivos do projeto. }(\mathrm{A})\end{array}$ & 17,28 & 30 \\
\hline Planejamento & $\begin{array}{l}\text { As medições emitidas pelo } \\
\text { departamento estão coincidentes com os } \\
\text { prazos estabelecidos e representando } \\
\text { fielmente o escopo de medição aplicável } \\
\text { ao período. (F) }\end{array}$ & 16,66 & 40 \\
\hline
\end{tabular}

Quadro 3: Itens com alto potencial relativo de eficiência e vantagem operacional para a organização.

Fonte: Elaborado pelos autores 
* os índices relativos de risco e eficiência e vantagem operacional correspondem aos produtos do grau de importância e a respectiva nota média do item de apoio mencionado.

Os resultados obtidos pelas pesquisas caracterizam uma fotografia momentânea da percepção do gerente de projetos. Neste trabalho, não foi possível identificar a variação temporal do nível de maturidade em processos relacionados à gestão de projetos. No entanto, destaca-se a crescente exigência por sistemáticas e processos melhor estruturados, em decorrência de projetos mais complexos e de maior valor agregado que a organização vem executando nos últimos doze anos. Percebeu-se que lacunas sistêmicas e falhas de maturidade podem comprometer o resultado dos projetos.

Verifica-se que mesmo a organização trabalhando integralmente com as recomendações do PMBOK e com um manual próprio para atuação do gerente de projetos desde 2008, o quinto nível de maturidade proposto por Kerzner (2007), não foi plenamente alcançado. Neste estágio, a organização deveria melhorar continuamente a partir do que foi aprendido, porém se comparados à projeção, os resultados foram recorrentemente inferiores à medida que os anos passaram, demonstrando que o acréscimo de exigência de maturidade não foi completamente suprido ao longo do período estudado. Quanto ao modelo Modelo OPM3 (PMI, 1999), a organização transita entre a quinta e a décima capacitação, por executar todas elas, mas não de forma plena. Este trabalho colabora especificamente com a sétima capacitação: criar mecanismos para avaliar a competência dos recursos/equipes de projetos.

Sobre a percepção dos gerentes de projetos do nível de integração entre os departamentos de apoio e a gerência de projetos, concluiu-se que a organização conta com uma estrutura operacional composta por itens de alta importância e ao mesmo tempo, baixo nível de desempenho sistêmico. De maneira análoga, o cenário oposto, formado por itens de alta importância e alto desempenho operacional sistêmico também existe. A partir da análise destes fatores, foi possível identificar e mapear, no cenário atual da empresa, itens que possuem alto potencial relativo de vantagem operacional e outros com alto nível relativo de risco potencial.

Conforme a literatura científica, é preciso atentar-se para as três camadas de competências: individual, de equipe e organizacional. A 
conjunção de todas elas a partir dos conhecimentos, habilidades e capacidade de solucionar problemas multidisciplinares possibilitam conduzir projetos de forma eficaz, executando-os e entregando-os com alto valor agregado (Frame, 1999 como citado em Rabechini \& Pessôa, 2005; Rabechini \& Pessôa, 2005). Tratando-se do nível de influência das áreas de apoio matricial da organização no resultado dos projetos, verificou-se que certas competências mencionadas seriam de forte centralização e responsabilidade dessas áreas, consequentemente possuem um alto nível de influência matricial. Adicionalmente, foi possível reconhecer pontos de baixa influência matricial com forte centralização em projetos, igualmente importantes. Identificou-se também competências que, para uma estruturação adequada, mereceriam composição entre o departamento de gerenciamento de projetos e áreas matriciais, sugerindo uma integração matricial participativa.

A análise qualitativa dos dados sugere forte influência dos pontos de integração ou centralização de responsabilidade matricial nos resultados dos projetos. Posto isso, é possível concluir que competências matriciais mal estruturadas dentro dos projetos proporcionam desdobramentos negativos tais como: lacunas de desempenho operacional, agregação de riscos ao projeto, não atendimento ao nível de maturidade exigido pelo projeto, entre outros (Kerzner, 2007; PMI, 2013).

Verificou-se também, que no quadro atual, há uma grande exigência relacionada ao grau de envolvimento e conhecimento dos gerentes de projetos em itens de controle e processos sistêmicos específicos. Este alto nível de exigência foi representado pela Figura 5 e sugere estruturação, fortalecimento e manutenção de competências gerenciais por meio de planos de treinamento e necessariamente a melhora dos processos de comunicação e controles existentes na organização, parte da curva de aprendizagem para atingir a excelência em gestão de projetos.

\section{CONSIDERAÇÕES FINAIS}

As técnicas de gestão de projetos e as competências que contribuem para a maturidade da organização tem forte correlação com os conceitos de administração e posicionamento estratégico. Uma adequada estruturação 
que leve em conta a amplitude destes tópicos possibilita à organização desenvolver competências operacionais sistêmicas que, em longo prazo, podem representar pontos reais de vantagem competitiva.

Com relação ao objetivo do trabalho, foi possível identificar o nível de competências e conhecimentos em gestão de projetos das áreas de apoio matricial e dos próprios gerentes. Adicionalmente, foi possível promover uma ponderação de importância das competências para o resultado do projeto.

Os achados deste trabalho têm potencial para auxiliar a organização na busca por vantagem competitiva, tendo em vista que a gestão de projetos já é considerada uma ferramenta de apoio à sua estratégia de fornecer solução total e eficiente ao cliente (Hax \& Wilde II, 2002). Ademais, é preciso considerar que a estratégia da organização e a gestão de projetos devem estar alinhadas e considerar essencialmente: a seleção do portfólio de projetos, o nível de competência existente e a própria concepção do negócio (Bouer \& Carvalho,2005). Este trabalho colabora para uma atuação direcionada à eliminação das lacunas, minimizando os riscos relativos ou alavancando os itens que aumentam potencialmente a vantagem operacional.

Este estudo conta com algumas limitações, inerentes à metodologia de estudo de caso e outros decorrentes da prática, são elas: (a) ênfase nos aspectos perceptivos - os levantamentos consideram a percepção das pessoas frente aos aspectos de pesquisa apresentados, podendo resultar em dados distorcidos face à subjetividade das respostas; (b) limitações de amostra - o questionário foi distribuído para todo o corpo de gerentes de projetos ativos na empresa mas, apesar da abrangência da coleta realizada, a amostra pode se caracterizar como pequena, levando em consideração o mercado existente de montagens industriais e os respectivos profissionais atuantes; (c) restrição da percepção em face de uma realidade momentânea, desconsiderando evoluções ou distorções desta percepção ao longo do tempo.

Trabalhos futuros poderiam avaliar a influência do nível de competências e maturidade em gestão de projetos em organizações de outros setores, de forma a confirmar o papel daquelas que apresentam potencial risco ou vantagem. Outra possibilidade seria realizar pesquisa similar com os gerentes funcionais, confrontando o resultado com a percepção dos gerentes de projetos. 


\section{REFERÊNCIAS}

APICS - American Production and Inventory Control Society. (2010). APICS Dictionary. 13th Edition (Revised).

Borges, F. H., \& Dalcol, P. R. (23 a 25 de Outubro de 2002). INDÚSTRIAS DE PROCESSO : COMPARAÇÕES E CARACTERIZAÇÕES. XXII Encontro Nacional de Engenharia de Produção.

Bouer, R., \& Carvalho, M. M. (2005). Metodologia singular de gestão de projetos: condição suficiente para a maturidade em gestão de projetos? Revista Produção, 347 - 361.

Brandão, H. P., \& Borges-Andrade, J. E. (2001). Causas e efeitos da expressão de competências no trabalho: para entender melhor a nocão de competência. Revista de Administração Mackenzie, 32-49.

Carvalho, M. M., \& Rabechini, R. J. (2011). Fundamentos em Gestão de Projetos: Construindo Competências para Gerenciar Projetos. Atlas.

Confederação Nacional da Indústria (CNI). (2011). Metodologia dos Indicadores Industriais. Brasília.

Crawford, J. K. (2010). The Strategic Project Office. CRC Press.

Dutra, J. S., Hipólito, J. A., \& Silva, C. M. (Jan/Abr de 2000). Gestão de pessoas por competências: o caso de uma empresa do setor de telecomunicações. Revista de Administração Contemporânea, pp. 161-176.

Fleury, M. T., \& Fleury, A. (2001). Construindo o Conceito de Competência. RAC, Edição Especial, 183-196.

Hax, A. C., \& Wilde II, D. L. (Setembro de 2002). The Delta Model - Toward a Unified Framework of Strategy. Working Paper.

Instituto de Pesquisa Econômica (IPEA). (2008). Principais características da inovação na indústria de transformação no Brasil. Brasília. João, B. N., \& Piscopo, M. R. (out-dez de 2006). Estatégias de inovação de valor e o Modelo Delta: o caso Zara. Revista Eletrônica de Gestão de Negógios, pp. 26-50.

Kerzner, H. (2007). Gestão de Projetos - As melhores práticas. São Paulo: Bookman. 
Kerzner, H. (2009). Project Management: A Systems Approach to Planning, Scheduling, and Controlling. New Jersey: John Wiley \& Sons.

Martins, G. d., \& Theóphilo, C. R. (2009). Metodologia da Investigação Científica para Ciências Sociais Aplicadas. São Paulo: Atlas.

PMI (2013). Um Guia do Conhecimento em Gerenciamento de Projetos (Guia PMBOK). São Paulo: Saraiva.

PMSURVEY. (19 de Maio de 2012). PM SURVEY.ORG. Fonte: PM SURVEY.ORG: http://www.pmsurvey.org

Porter, M. E. (1996). What is Strategy? Harvard Business Review, 6178.

Project Managment Institute. (1999). Organizational project management maturity model (OPM3). Fonte: http://www.pmi.org

Rabechini, R. J., \& Pessôa, M. S. (Jan./Abr. v. 15 n.1 de 2005). Um modelo estruturado de competências e maturidade em gerenciamento de projetos. Revista Produção, pp. 34-43.

Ruas, R. (2005). Os Novos Horizontes de Gestão: Aprendizagem Organizacional e Competências. São Paulo: Artmed Editora SA.

Sauser, B. J., Reilly, R. R., \& Shenhar, A. J. (2009). Why projects fail? How contingency theory can provide new insights - A comparative analysis of NASA's Mars Climate Orbiter loss. International Journal of Project Management, pp. 665-679.

Thamhain, H. J. (mai./ago. de 2012). The Changing Role of Team Leadership in Multinational Project Environments. Revista de Gestão e Projetos - GeP, pp. 04-38.

Vasconcellos, E., \& Hemsley, J. R. (2002). Estrutura das Organizações. São Paulo: Thomson Piorneira.

Yin, R. K. (2010). Estudo de Caso - Planejamento e Métodos. São Paulo: Bookman. 